\title{
LIVROS ESCOLARES: O ELEMENTO CENTRAL DO TRABALHO DIDÁTICO
}

\author{
SCHOOL BOOKS: ELEMENT CENTRAL EDUCATIONAL WORK
}

Jemerson Quirino de Almeida ${ }^{1}$

\begin{abstract}
Resumo
Neste artigo buscamos aproximar o leitor a algumas discussões sobre os livros escolares brasileiros. Nosso objetivo específico é demonstrar que estes instrumentos pedagógicos se tornaram os principais elementos do trabalho didático nas escolas de educação básica. Para tanto, faremos uma revisão bibliográfica com autores que discutem o tema. Não buscamos esgotar todas as problemáticas que envolvem o assunto. Antes, temos a intenção de desenvolver discussões que, doravante, nos possibilitem refletir sobre a organização do trabalho didático na educação contemporânea. Nesse sentido, acreditamos que, para alcançarmos os objetivos almejados neste estudo, é necessário fazer um recuo no tempo para compreender a origem da escola moderna. Sendo assim, é fundamental apresentarmos a proposta de Comenius de "ensinar tudo a todos", disposta em sua obra: a Didáctica Magna. Destarte, pontuamos que nosso artigo compactua com uma concepção teórica específica que se põem a investigar os instrumentos do trabalho didático e seu papel na relação educativa na sociedade burguesa. Procuramos, à luz da leitura de autores clássicos e da teoria marxista, compreender as relações que envolvem a organização do trabalho didático no ambiente escolar.
\end{abstract}

Palavras-chave: Livros escolares. Trabalho didático. História da educação brasileira.

\begin{abstract}
In this article we seek to approximate the reader to some discussions about Brazilian schoolbooks. Our specific goal is to demonstrate that these pedagogical instruments have become the main elements of the didactical work in elementary schools. Therefore, we will do a bibliographical review with authors who discuss the topic. We do not seek to exhaust all the issues surrounding the subject. Before, we intend to develop discussions that henceforth enable us to reflect on the organization of didactical work in contemporary education. In this direction, we believe that to achieve the objectives pursued in this study, it is necessary to go back in the past to comprehend the origin of the modern school. Therefore, it is fundamental that we present the proposal from Comenius of "teach everything to everyone", arranged in his work: the Didactic Magna. Thus, we pointed out that our article condones a particular theoretical conception that purposes to investigate the instruments of the didactical teaching and its role in the educational relationship in bourgeois society. We seek on a reading of classical authors and the Marxist theory to comprehend the relations that involve the organization of the didactical work in the school environment.
\end{abstract}

Keywords: School books. Didactical work. History of Brazilian education.

\footnotetext{
${ }^{1} \mathrm{O}$ autor é docente na Universidade Estadual de Mato Grosso do Sul (UEMS de Paranaíba). Doutorando da Universidade Estadual de Mato Grosso do Sul (UFMS de Campo Grande) e Mestre em Educação pela UEMS de Paranaiba. E-mail: jemersonalmeida@yahoo.com.br
} 


\section{INTRODUÇÃO}

Neste artigo $^{2}$ buscamos aproximar o leitor a algumas discussões sobre os livros escolares brasileiros. Nosso objetivo é demonstrar que estes instrumentos pedagógicos se tornaram os principais elementos do trabalho didático nas escolas. A organização do trabalho didático na escola contemporânea pauta-se na relevante função atribuída aos livros escolares. A origem desse processo se deu no século XVII com Comenius. O autor compôs a sua obra em meio às necessidades postas pelo contexto da época: a manufatura, o nascente capitalismo e a Reforma Protestante. Nosso interesse pela questão se dá porque os principais elementos da organização do trabalho didático, presentes ainda nos dias atuais, resultam do trabalho de Comenius. A sua influência é percebida até hoje na seriação dos conteúdos, na divisão do trabalho didático e nos instrumentos empregados na relação educativa. Porém, cabe lembrar que os textos escolares utilizados no Brasil, desde a implantação da escola moderna só recentemente seguiram esta dinâmica de produção. Essa tese é explorada largamente por Gilberto Luiz Alves (2001, 2005, 2011, 2012).

No século XIX, por exemplo, os professores tinham controle sobre o instrumento de trabalho e os livros eram, em alguns casos, confeccionados por eles próprios. Os textos eram mais longos e complexos, o que se distancia da proposta comeniana, pois nesta o professor apenas executa tarefas pré-determinadas pelo manual escolar (ALVES, 2011). Com base nessa constatação, acreditamos que para alcançarmos os objetivos almejados neste artigo, é necessário fazer um recuo no tempo para compreender a origem da escola moderna. Nesse sentido, é fundamental refletirmos sobre a proposta de Comenius de "ensinar tudo a todos", apresentada em sua obra: a Didáctica Magna.

Diante do que foi observado, é relevante destacar que as investigações ligadas à área de História e Educação vêm, desde a segunda metade do século XX, desenvolvendo análises que tomam os livros escolares como fonte de pesquisa. De acordo com Fernandes (2005), a partir de 1960:

O grande clássico e referência para todos os trabalhos que se seguiram foi a obra de Umberto Eco e Mariza Bonazzi, Mentiras que parecem verdades, traduzido em diversos idiomas. No Brasil, o livro As Belas Mentiras: a ideologia subjacente aos

\footnotetext{
${ }^{2}$ Este artigo é parte de um estudo que resultou em dissertação de mestrado sobre os instrumentos do trabalho didático utilizados no ensino de História no Brasil.
} 
textos didáticos, de Maria de Lourdes Deiró Nosella fez escola, sendo ainda hoje referência em qualquer bibliografia sobre livro didático. (FERNANDES, 2005, p. 123-124).

O autor complementa que, a partir da década de 1980, houve uma renovação dos estudos sobre múltiplas temáticas ligadas à análise das edições didáticas, como a História da leitura e do livro no Ocidente:

\begin{abstract}
A partir da década de 80 , em parte pela renovação da História Cultural, com as contribuições teóricas advindas da obra de Roger Chartier e Robert Darton que inovaram os estudos acerca da história da leitura no mundo ocidental, houve mudanças de abordagens nas pesquisas relacionadas ao livro didático. Hoje, os trabalhos estão mais direcionados a questões relativas ao uso e apropriação do livro didático por alunos e professores, às práticas de leitura, entre outros. Assim, segundo Alain Choppin, a história da edição escolar constitui, hoje, um dos campos mais promissores da História da Educação e novas questões se colocam para os historiadores, tais como: a relação entre livro didático e a formação de professores; o livro didático e sua interferência no currículo escolar; o uso do livro didático por parte do aluno; sua utilização na educação não-formal; a linguagem e imagem utilizada nos livros didáticos; o perfil sociológico dos autores; o papel das mulheres na elaboração e difusão dos saberes escolares. (FERNANDES, 2005, p. 124)
\end{abstract}

Para além dos apontamentos feitos por Fernandes, observam-se outras propostas de análises, como as de Kazumi Munakata e Célia Cristina de Figueiredo Cassiano, que abordam o livro didático como mercadoria. A última ratifica em seus estudos os interesses de grandes companhias multinacionais no mercado brasileiro de livros didáticos. Para ela, "As atuais editoras de livros didáticos, que dominam o mercado brasileiro, ao lado dos investidores financeiros por trás de universidades privadas, são protagonistas da inserção do Brasil, no setor da Educação, na economia globalizada" (CASSIANO, 2004, p. 8). A autora denuncia também a formação de cartel entre as editoras de materiais didáticos que dominam o mercado nacional. Para isso, ela recorre aos estudos de Coulon e Pedro (1995 apud CASSIANO, 2004, p. 9), que afirmam: "O cartel reparte o mercado de vendas, fixa a quantidade de produtos a fabricar, determina os preços e distribui os lucros entre as diferentes empresas". Para Cassiano isso representa a desnacionalização da produção do livro didático no Brasil ${ }^{3}$.

\footnotetext{
${ }^{3}$ Cassiano discute a inserção do Brasil no "mercado ibero-americano" do livro e a entrada dos espanhóis no país. Ver: $O$ mercado do livro didático no Brasil: da criação do Programa Nacional do Livro Didático (PNLD) à entrada do capital internacional espanhol (1985- 2007). Tese de doutorado defendida por Célia Cristina de Figueiredo Cassiano em 2007 junto ao programa de Pós-graduação Educação: História, Política e Sociedade da PUC - SP.
} 
O livro de Décio Gatti Júnior, A escrita escolar da História: livro didático e ensino no Brasil (1970-1990,) também apresenta uma valiosa contribuição sobre a produção e utilização de livros escolares entre as décadas de 1960 e 1990. Gatti Júnior (2004) discute o processo de massificação do ensino brasileiro, por meio de entrevistas com autores e editores de livros didáticos, sua análise sobre um vasto material, chegando segundo o próprio autor, ao número aproximado de 350 livros somando cerca de 50 coleções (GATTI JÚNIOR, 2004, p.20), nos permiti perceber que as relações postas na produção e incorporação dos livros didáticos nos referidos períodos estão muito distantes de serem preocupações estritamente pedagógicas, mas sim, alinhadas aos interesses e nuances do sistema capitalista.

Outro ponto que os estudiosos buscam compreender é o fato de que as disciplinas ligadas às ciências humanas, principalmente Geografia e História, com seus respectivos livros didáticos, foram utilizados no ensino escolar como um dos elementos difusores do conhecimento oficial. Segundo Fonseca (1999), os manuais “[...] atuam, na verdade, como mediadores entre concepções e práticas políticas e culturais, tornando-se parte importante da engrenagem de manutenção de determinadas visões de mundo" (FONSECA, 1999, p. 204). Muitas pessoas desconhecem a eficácia do livro didático como formador de opiniões, considerando-os como inofensivos ou neutros. Além do que, como observaram Lajolo e Zilberman (1999), o "livro didático" é considerado o "primo pobre" da literatura; por isso, acabam esquecidos, abandonados ou jogados fora, após o esgotamento de sua validez ou mudança de nível escolar do aluno. Assim, devemos encará-los sobre variados aspectos pedagógicos, políticos, econômicos e culturais.

Destarte, pontuamos que em nosso artigo compactuamos com uma concepção teórica específica que se põem a investigar os instrumentos do trabalho didático e seu papel na relação educativa na sociedade burguesa. Procuramos, à luz da leitura de autores clássicos e da teoria marxista, compreender as relações que envolvem a organização do trabalho didático no ambiente escolar. Neste caminho, destacam-se como referência Alves (1990, 1995, 2001, 2004, 2005, 2011, 2012), Alves \& Centeno (2009), Centeno (2007, 2009, 2010, 2011), Saviani (2006, 2007, 2010), Brito et al. (2010), Brito (2012), Souza (2010) e Lancillotti (2013). 


\section{COMENIUS: COMO "ENSINAR TUDO A TODOS"}

Comenius foi um pastor protestante, nascido na Morávia ${ }^{4}$, em 1592. Viveu o calor da Reforma Protestante, movimento que teve início com Martinho Lutero no século XVI. A Reforma buscava combater os privilégios da Igreja Católica, questionando o monopólio que essa instituição detinha sobre a interpretação das Sagradas Escrituras. Para os protestantes, todos - inclusive os trabalhadores mais humildes - deveriam ter livre acesso à leitura da Bíblia. Pouco à frente, esse pensamento desembocaria em dois pontos importantes para o desenvolvimento da escola moderna: primeiro, que a Bíblia fosse traduzida do latim para língua vulgar e, segundo, que a população tivesse o mínimo necessário de instrução para a leitura.

Desse modo, tendo em vista o contexto histórico em que estava inserida a proposta comeniana, podemos afirmar que ela se apresentava como revolucionária e extremamente avançada. A Comenius coube dar forma ao que hoje conhecemos como escola moderna. Como afirma Alves:

Comenius está na origem da escola moderna. A ele, mais do que a nenhum outro, coube o mérito de concebê-la. Nessa empreitada, foi impregnado pela clareza de que o estabelecimento escolar deveria ser pensado como uma oficina de homens (ALVES, 2004, p. 81, grifos no original).

O modelo de trabalho em que Comenius se inspirou foi a manufatura ${ }^{5}$. Assim, foi possível atender a demanda e reduzir os custos, ao se produzir mais em menor tempo; diferentemente do artesanato, no qual o domínio da técnica de confecção permite ao artesão ser o senhor de seu produto, confeccionando, porém, um número reduzido de peças. Podemos,

\footnotetext{
${ }_{5}^{4}$ A Morávia é uma região da Europa central que constitui atualmente a parte oriental da República Checa.

${ }^{5}$ Segundo Marx a origem da manufatura parte da cooperação baseada na divisão do trabalho artesanal. De acordo com ele sua origem é dúbia: "De um lado, ela parte da combinação de ofícios autônomos de diferentes espécies, que são despidos de sua autonomia e tornados unilaterais até o ponto em que constituem apenas operações parciais que se complementam mutuamente no processo de produção de uma única e mesma mercadoria. De outro lado, ela parte da cooperação de artífices da mesma espécie, decompõe o mesmo ofício individual em suas diversas operações particulares e as isola e as torna autônomas até o ponto em que cada uma delas torna-se função exclusiva de um trabalhador específico. Por um lado a manufatura introduz, portanto, a divisão do trabalho em um processo de produção ou a desenvolve mais; por outro lado, ela combina ofícios anteriormente separados. Qualquer que seja seu ponto particular de partida, sua figura final é a mesma - um mecanismo de produção, cujos órgãos são seres humanos" (MARX, 1983. p. 268).
} 
então, refletir analogicamente acerca da proposta comeniana: ao artesanato, equipara-se o modelo de ensino praticado até a Reforma, no qual predominava a relação preceptoral entre mestre e pupilo, estabelecida desde a Antiguidade; ao trabalho manufatureiro, pode ser relacionada a proposta do pedagogo protestante.

Centeno (2009) com base na teoria desenvolvida por Alves afirma que:

À época, o conhecimento era predominantemente veiculado pela ação de mestres ou preceptores, detentores de vastos conhecimentos, sábios por excelência. O preceptor era dotado de sólida formação humanística e seu trabalho era complexo por que exigia o domínio amplo do conhecimento e, por essa razão, seus estipêndios eram elevados. $\mathrm{O}$ ensino era ministrado individualmente ou em pequenos grupos e não estava regido por um plano de estudos, divisão por séries ou por graus de adiantamento. Os conteúdos didáticos, na forma de extratos, eram retirados dos clássicos e as vertentes das fontes variavam conforme as diferentes conjunturas históricas. Não havia, à época, ambientes reservados para o ensino como prédios escolares. Os espaços em que se realizava o trabalho educativo eram públicos, abertos, a exemplos das praças e jardins, ou privados, em ambientes reservados da casa do discípulo ou do preceptor. (CENTENO, 2009, p. 170).

Ao reconhecer as dificuldades de se estender tal modelo, devido aos altos custos e ao reduzido número de pessoas hábeis ao trabalho docente, Comenius buscou, no modelo de divisão do trabalho manufatureiro, a solução para o grande impasse que impossibilitava “ensinar tudo a todos". A esse respeito, Alves (2004) sintetiza que:

[...] o educador morávio pressupunha uma organização para a atividade de ensino, no interior da escola, que visava equipará-la á ordem vigente nas manufaturas, onde a divisão do trabalho permitia que diferentes operações, realizadas por trabalhadores distintos, se desenvolvessem de forma rigorosamente controlada, segundo um plano prévio e intencional que as articulava, para produzir mais resultados com economia de tempo, de fadiga e de recursos. (ALVES, 2004, p. 83).

A divisão do trabalho, porém, não fora suficiente para colocar em prática a proposta comeniana. Era necessário criar também um instrumento que viabilizasse o trabalho docente. Para isso, Comenius desenvolveu o que ele chamou de "livros pan-methodicos". Segundo ele, os livros pan-metódicos eram de suma importância para o desenvolvimento de seu projeto educacional:

Uma só coisa é de extraordinária importância, pois, se ela falta, pode tornar-se inútil toda uma máquina tão bem construída, ou, se está presente, pode pô-la em movimento: uma provisão de livros pan-metódicos. Efetivamente, da mesma maneira que, fornecendo o material tipográfico, é fácil encontrar quem possa, saiba e queira utilizar, e quem ofereça qualquer soma para imprimir bons e úteis livros, e quem compre esses livros, de preço acessível e de grande utilidade, assim também 
seria fácil, uma vez preparados os meios necessários para a pan-didática, encontrar os fautores, os promotores e os diretores de que ela precisa. (COMENIUS, 2001, p. $535)$.

Deste modo, a preparação dos materiais é o elemento central que possibilitaria colocar a "máquina" em funcionamento. Para tanto, Comenius chamou a atenção da necessidade de eleger autores hábeis a confeccionar os livros escolares e, alertou sobre a produção do material não ser tarefa de um único homem:

E esta preparação depende da constituição de uma sociedade de homens doutos,
hábeis, ardorosos para o trabalho, associados para levar a bom termo uma empresa
tão santa, e nela colaborando, cada um segundo seus meios. Mas esta empresa não
pode ser obra de um só homem, principalmente se está ocupado em outras coisas, e
não tem conhecimento de tudo aquilo que é necessário colocar na pan-metódica; e
talvez até, para realizar tal trabalho, não seja suficiente a vida de um homem, se tudo
se fizer dentro da máxima perfeição. É necessário, portanto, uma sociedade de
pessoas escolhidas. (COMENIUS, 2001, p. 535-536).

A metodologia de ensino universal, exposta por Comenius, promovia o barateamento dos custos. De acordo com Centeno (2009), “Com a revolução no instrumental, expressa no surgimento do manual didático, qualquer homem de capacidade intelectual mediana poderia ensinar”. (CENTENO, 2009. p. 172).

O projeto de Comenius, entretanto, não pôde ser colocado em prática de imediato. Suas contribuições surtiriam efeito à frente, por volta do século XIX, quando a necessidade de expandir a educação já se fazia presente. No Brasil, a proposta comeniana só foi introduzida, de fato, na primeira metade do século XX. Segundo Centeno (2010) no século XIX:

\begin{abstract}
Os livros didáticos eram complexos e elaborados pelos próprios professores; foram incorporados em sala de aula como instrumentos auxiliares do docente. A universalização do ensino, realizada somente após os anos 1930 impôs a adoção desse instrumento que foi ficando cada vez mais simplificado. O manual comeniano, de tamanho pequeno, que apresenta as coisas sumariamente, de muitas coisas com poucas palavras, de grande utilidade com muitas imagens foi algo que se difundiu no Brasil após a universalização do ensino. (CENTENO, 2010, p. 32).
\end{abstract}

Se o manual comeniano tardou em vigorar no Brasil, os "materiais da Contrarreforma", por sua vez, se faziam presentes desde o princípio da colonização, por meio dos colégios fundados pela Companhia de Jesus. Tais colégios mantinham, como instrumentos do trabalho didático, praticamente as mesmas fontes do período medieval, mudando apenas a maneira de operá-los. Devido aos avanços da imprensa e ao caráter 
ideológico assumido pela Igreja Católica frente aos questionamentos da época, foram utilizados, nesse empreendimento pedagógico, extratos das obras clássicas ${ }^{6}$ (ALVES, 2012). De acordo com Alves (2012), os colégios jesuíticos influenciaram na consolidação do material impresso como recurso didático:

\begin{abstract}
Como os extratos das obras clássicas se disseminaram na condição de recursos didáticos mais apropriados à relação educativa, nos colégios da Companhia de Jesus estavam criadas as condições para que vicejassem, sob a forma de livros impressos, instrumentos didáticos compostos por trechos selecionados dessas fontes. A precariedade dos recursos disponíveis, o elevado custo dos livros e a necessidade de controle ideológico das informações viabilizavam a produção de antologias e de seus similares, os florilégios e as seletas, tão difundidos na escola brasileira até o segundo terço do século XX (ALVES, 2012, p. 6).
\end{abstract}

Os materiais de uso na organização do trabalho didático só se alterariam mais tarde, no século XVIII, com a realização das reformas Pombalinas. Em 1759, a Companhia de Jesus foi expulsa de Portugal e do Brasil pelo então ministro de Estado de Portugal, Marquês de Pombal, cujas reformas empreendidas eram de cunho econômico, político e cultural. A partir desse momento, intensificou-se a presença do Estado português na educação brasileira ${ }^{7}$. No entanto, de modo geral, os estudantes brasileiros continuaram tendo que completar seus estudos na Europa.

Tais mudanças na educação brasileira desembocaram, posteriormente, na fundação de novos centros educacionais. Em 1800, foi inaugurado no Brasil o Seminário de Olinda. De acordo com Alves:

O colégio-seminário pombalino teve notável participação no processo de modernização burguesa do reino, pois foi concebido, também, para realizar a função decisiva de preparar quadros, no interior do clero católico, visando levantar as riquezas naturais do reino, condição prévia de seu aproveitamento econômico. (ALVES, 2001, p. 7).

\footnotetext{
${ }^{6}$ Segundo Alves: “[...] as obras clássicas não eram lidas e estudadas na íntegra dentro dos colégios jesuíticos, o que mudava a tendência dominante no ensino preceptorial até então. Mas, por meio dos extratos, os estudantes continuavam tendo acesso aos textos dos trágicos, dos comediógrafos, dos oradores, dos filósofos gregos e latinos. Esses extratos eram centrais no trabalho didático [...]". (ALVES, 2012).

${ }^{7}$ Esta questão está bem desenvolvida no texto de Dermeval Saviani (2007), História das idéias pedagógicas no Brasil.
} 
Acerca dos materiais de uso escolar, algumas mudanças foram constatadas por Alves (2001) ao analisar o Seminário de Olinda, como o abandono do veto a alguns clássicos e aos expurgos:

Sob o influxo das reformas pombalinas da instrução pública e da orientação política conferida pelo iluminismo luso-brasileiro, nele foi superada a prática de expurgos de obras clássicas usadas como recursos didáticos e instaurado ambiente de maior tolerância política (ALVES, 2001, p. 137-192).

Dentre as novidades apresentadas pelo Seminário de Olinda, estão novos termos como: compêndios e resumos. Sobre o emprego dos compêndios como instrumento do trabalho didático nos colégios pombalinos é importante esclarecer que segundo Alves (2012):

\begin{abstract}
Tanto quando recomendava o emprego de instrumentos modernos de uso disseminado, como quando permitia aos professores compendiar 'algum dos Tratados' de certa matéria, o compêndio passava a incluir um significado que ia além de sua relação estrita com os textos e os autores clássicos. Isto é, continuava sendo 'resumo de uma teoria, ciência, doutrina', mas começava a tornar-se, por sua destinação, 'livro, esp. escolar, que enfeixa tal resumo' (Houaiss; Villar, 2001, p. 774). O que se difundiu no Brasil, ao longo do século XIX, foi esse significado do termo compêndio associado à sua utilização na escola e, quanto à autoria, a professores das correspondentes matérias que exerciam o magistério nos principais estabelecimentos escolares do País, em especial no Colégio Pedro II. Em paralelo, ocorreu o progressivo desuso daquele outro significado, referido nos Estatutos, que ligava o compêndio às obras e aos autores clássicos. Essa precisão conceitual estava associada ao maior grau de especialização que o próprio instrumento de trabalho ganhara. Especializando-se, também o seu significado se especializou para tornar-se capaz de traduzi-lo como o que de fato passava a ser: instrumento de trabalho didático inteiramente vinculado à escola, ao professor e à função que exercia na relação educativa. (ALVES, 2012, p. 13).
\end{abstract}

Foram também incorporados ao trabalho didático textos especializados, confeccionados por professores ou pensadores das respectivas áreas, e não somente por autores clássicos (ALVES, 2012). Cabe ressaltar que o uso dos textos clássicos não foi abandonado por inteiro nesse período.

Outras mudanças na educação brasileira se deram com a chegada da corte portuguesa. Em 1808, foram instalados alguns cursos para elevar o nível da capital (Rio de Janeiro) aos patamares da corte. Com a volta do rei a Portugal, em 1821, e a independência proclamada por D. Pedro I em 1822, a educação passou a ser colocada em pauta como uma questão nacional. Dentre as contribuições do período imperial, na área da educação, destaca-se a criação do Colégio Pedro II em 1837. Essa instituição tinha como propósito formar os 
quadros de eruditos necessários à sociedade e servindo ainda de modelo de ensino secundário para os demais colégios do Brasil.

No que se refere aos instrumentos de trabalho didático, o Colégio Pedro II passou a incorporar definitivamente textos escolares que ficaram conhecidos como compêndios. Como atesta Alves (2012): “A experiência desse colégio demonstra que os compêndios passaram a dominar amplamente o universo dos textos didáticos difundidos nas matérias de seu plano de estudos". (ALVES, 2012, p. 15).

O domínio ao qual se refere o autor perdurou até praticamente as primeiras décadas do século XX. Nas últimas décadas do século XIX, ocorreu uma série de acontecimentos relevantes no Brasil, como a abolição da escravatura em 1888 e a Proclamação da República em 1889. Porém, foi somente após o final da Primeira Guerra Mundial, por volta de 1920, que o cenário econômico, cultural e político praticamente forçou o Brasil a se reorganizar socialmente.

Na década de 1930, depois do golpe militar que levou Getúlio Vargas ao poder, começou a ser colocado em prática no Brasil um Programa de Reconstrução Nacional, que, diante das novas necessidades brasileiras, buscava adequar e inserir o país na dinâmica de mundo daquela época. De acordo com Centeno (2007), o Programa de Reconstrução Nacional:

[...] segundo o discurso oficial, visava a aumentar a presença do Estado em todos os setores da vida nacional, para superar o grave desequilíbrio econômico causado pela queda de preços do café, prevenir o país contra outras possíveis crises e, sobretudo, integrar a nação e defender a sua soberania. (CENTENO, 2007, p. 16).

Nessa direção, crescia cada vez mais o interesse do Estado pela questão educacional. O que se explicita na criação ainda em 1930 do Ministério da Educação e Saúde Pública ${ }^{8}$. A educação escolar era vista como um importante instrumento para a reconstrução do país. $\mathrm{Na}$ concepção de Marta M. de Araújo (2007), os projetos educacionais se sustentavam pela

\footnotetext{
${ }^{8}$ Segundo informações do site do MEC: “[...] a instituição desenvolvia atividades pertinentes a vários ministérios como saúde, esporte, educação e meio ambiente. Até então, os assuntos ligados à educação eram tratados pelo Departamento Nacional do Ensino, ligado ao Ministério da Justiça". Só a frente em 1953, com a autonomia da área da saúde, o ministério mudaria de nome e passaria a se chamar Ministério da Educação e Cultura (MEC) Cf. Disponível em: <http://portal.mec.gov.br>
} 
crença de que a educação tinha o poder de moldar a sociedade pela reforma das mentalidades ${ }^{9}$. Para tanto, segundo a autora:

Num quadro de revoluções tecnológicas com seus desdobramentos no modo prático de viver, de trabalhar e de relacionar-se mental e materialmente, tornariam impositivo ao sistema de educação nacional condições de eficiência técnica e científica que os tempos estariam a reclamar. (ARAÚJO, 2007, p. 12).

No entanto, para nós, embora a questão das mentalidades estivesse de fato presente nos discursos oficiais da época, os principais pontos que desembocaram na necessidade da universalização da educação no Brasil, estão antes de tudo, ligados a algumas transformações ocorridas no país ainda na primeira metade do século XX, como o crescimento da população urbana, a entrada da mulher no mercado de trabalho, à definição da idade mínima para o trabalho na indústria, etc. Tais pontos promoveram um aumento da demanda escolar e favoreceram a massificação do ensino, que foi viabilizada por meio da incorporação do manual didático de tipo comeniano, em lugar dos compêndios no âmbito do uso escolar. Segundo Alves (2012): “O seu emprego e a sua difusão denotavam que, enfim, o Brasil enveredava por uma rota de desenvolvimento da escola moderna coincidente com a preconizada por Comenius". (ALVES, 2012, p. 21).

A proposta de universalização do ensino desembocou na confecção e adoção de um instrumento do trabalho didático caracterizado por Comenius como de tamanho pequeno, que apresenta "as coisas sumariamente, ou seja, muitas coisas com poucas palavras", (COMENIUS, 1997 apud CENTENO, 2010), de grande utilidade e com muitas imagens (CENTENO, 2010). Tal instrumento tirou das escolas os livros escolares classificados como compêndios e os clássicos: textos extensos, com linguagem rebuscada, confeccionados pelos próprios professores. Estes foram substituídos por um material prático, menor, com textos de

\footnotetext{
${ }^{9}$ No ponto de vista de Marta M. de Araújo o projeto de "educação escolar enquanto projeto político de formação de mentalidades colocava-se perante problemas sociais condizentes com a industrialização crescente; com o monopólio estatal da escolarização; com a demanda por escolas técnicas e profissionais; com os princípios de laicização do ensino, da escola única e gratuita para todos; enfim, com as formulações da Pedagogia Nova" (ARAÜJO, 2007, p. 10.) No entanto, a autora esclarece que vários projetos "cocorriam" ao propósito educacional: Citando outros autores: “[...] Havia projetos que defendiam uma educação escolar humanística sobre a técnica ou científica; que enfatizavam os ensinamentos religiosos e o culto do civismo contra o ensino agnóstico, laico e democratizante; que pregavam a escola única em lugar da escola para cada segmento social; que mantinham a posição do esforço do governo na educação das elites ao invés de priorizar a educação popular; e, ainda, aqueles que insistiam a uniformidade educacional e na padronização cultural em lugar da liberdade das políticas regionalistas". (SCHWARTZMAN; BOMENY; COSTA, 1984 apud ARAÚJO, 2007).
} 
mais fácil compreensão, que viabilizassem o ensino e, principalmente, facilitassem o papel do professor. Tal projeto visava a edificar e expandir a escola em todo o país, com praticidade e economia. Desde então, esse material didático mais simplificado converteu-se no elemento central do trabalho pedagógico. Sua influência na escola contemporânea é notória, facilitando e regendo o trabalho docente.

\section{OS LIVROS ESCOLARES NA EDUCAÇÃO BRASILEIRA}

Apesar de mais de dois séculos de "atraso" em relação ao desenvolvimento da educação em países capitalistas mais avançados, o Brasil, ao incorporar a proposta comeniana, pôde acelerar e massificar a educação básica. No entanto, a maneira em que se deu a organização do trabalho didático nas últimas décadas, focada na produção e utilização de livros escolares como elemento central na relação educativa, conferiu aos materiais escolares severas críticas. Desse modo, alguns autores pontuam sobre a relevância de melhorar a qualidade dos livros escolares. Outros, pelo contrário são incisivos quanto à necessidade de superação dos manuais didáticos.

Bittencourt (1998) defende novas formas para a utilização dos livros escolares. A autora tece críticas a tal instrumento do trabalho didático; no entanto, não se coloca contra a produção dos manuais escolares:

[...] O livro didático é limitado e condicionado por razões econômicas, ideológicas e técnicas. A linguagem que produz deve ser acessível ao público infantil e juvenil e isso tem conduzido a simplificações que limitam sua ação na formação intelectual mais autônoma dos alunos. Autores e editores ao simplificarem questões complexas impedem que os textos dos livros provoquem reflexões ou possíveis discordâncias por parte dos leitores. Sua tendência é de ser um objeto padronizado, com pouco espaço para textos originais, condicionando formatos e linguagens, com interferências múltiplas em seu processo de elaboração associadas à lógica da mercantilização e das formas de consumo. (BITTENCOURT, 1998, p. 73).

Para Bittencourt (1998), tais deficiências dos livros didáticos podem ser reduzidas e superadas mediante a ação de docentes e discentes em sala de aula. Nesse sentido, Bittencourt afirma que o livro didático é o principal instrumento de trabalho de professores e alunos (BITTENCOURT, 1998, p. 72).

Outra perspectiva interessante é de Souza (2010) que pontua: 
[...] nem todo livro didático deve ser combatido, como as antologias, por exemplo. Apenas as versões contemporâneas de um tipo de manual didático surgido no século XVII, que se decompôs e perdeu sua validade tal como ele se apresenta, para a contemporaneidade [...]. (SOUZA, 2010, p. 125).

Acerca dessa discussão, Centeno (2009) é radical, posicionando-se contra a reformulação e conservação do manual didático de tipo comeniano como instrumento do trabalho didático no espaço escolar:

Muitos educadores entendem que a questão se reduz a uma reforma dos manuais didáticos. De fato, não é possível aperfeiçoar o manual, pois o problema não está somente na ideologia e sim na função exercida por esse instrumento no trabalho didático. Ele se impõe como fonte única do conhecimento e exclui todas as demais. Exclui, portanto, o conhecimento culturalmente significativo, veiculado pelos livros clássicos e por sites das grandes bibliotecas e museus dos diversos continentes. A inserção de variadas fontes, novas tecnologias e de novas linguagens no trabalho didático tem ficado no plano do discurso. (CENTENO, 2009, p. 175).

O posicionamento da autora compactua com o de Gilberto Luiz Alves, que ratifica a necessidade de eliminação do manual didático:

[...] não basta diagnosticar as consequências do emprego do manual didático. Não basta execrá-lo e mudar o seu nome para livro escolar ou outra expressão considerada mais apropriada. Não basta, nem mesmo, a iniciativa de produzir textos de melhor qualidade quanto ao conteúdo, como demonstra Mianutti. A solidez com que os manuais didáticos comenianos se impuseram no trabalho didático nem sempre tem sido entendida pelos estudiosos como algo determinado pela organização do trabalho didático. Implicando uma organização técnica do trabalho, no caso de natureza manufatureira, ela envolve desde a relação educativa, os procedimentos do professor, os conteúdos didáticos, as tecnologias educacionais e o espaço físico da sala de aula. É um mecanismo no qual todos os elementos constitutivos, como engrenagens, se encontram em relação de interdependência e se reforçam mutuamente. O diferente não cabe dentro dele e é expelido. Portanto, está fadada ao fracasso qualquer iniciativa reformista que toque somente um de seus aspectos. (ALVES, 2012).

\section{O autor expõe em $O$ trabalho didático na escola moderna: formas históricas (ALVES,}

2005), importantes apontamentos que nos permitem pensar sobre a necessidade de superar a ordem educacional vigente, trata-se na visão de Alves de mudanças profundas que só se efetivaram por meio de uma revolução didático-pedagógica:

[...] é necessário que se reafirme a tarefa básica colocada presentemente para os educadores: a construção de uma nova didática. Torna-se imperativa a produção de uma nova organização do trabalho didático cujo fundamento deve ser buscado nos recursos tecnológicos contemporâneos. Isso se, por um lado, implica a 
impossibilidade de conciliação com a organização manufatureira do trabalho didático, não inviabiliza o aproveitamento de tecnologias de outras épocas. A nova forma preconizada não é excludente, tanto que se propõe a recuperar o livro clássico, expulso da escola pela excludente organização do trabalho didático inventada por Comenius, vigente ainda em nosso tempo. Não se deve esquecer que, objetivamente, o livro clássico se universalizou pelo barateamento propiciado pela revolução industrial e, mais ainda, com a automatização e que, hoje, já começa a ser disponibilizada pela internet e pelo suporte de outras tecnologias avançadas. Logo, a nova forma de organização do trabalho didático, comprometida com a necessidade de universalizar a cultura e, como decorrência, por colocar-se na perspectiva de democratização do conhecimento culturalmente significativo, não pode tolerar os instrumentos que se erigem à condição de obstáculos à realização da existência humana num patamar superior. (ALVES, 2005, p. 76).

De qualquer maneira, o fato é que, os manuais didáticos se fazem presentes no cotidiano escolar do Brasil e em diversos países no mundo. Como afirma Apple: "São os livros didáticos que estabelecem grande parte das condições materiais para o ensino e a aprendizagem nas salas de aula de muitos países através do mundo" (APPLE, 1995, p. 8). No Brasil, como já foi dito, os materiais de tipo comeniano foram introduzidos a partir do período Vargas e difundidos com a criação da Comissão Nacional do Livro Didático (CNLD 1938/1945) ${ }^{10}$. Porém, é importante lembrar que, de acordo com o Fundo Nacional de Desenvolvimento da Educação (FNDE) ${ }^{11}$, em 1929, o Estado já havia criado um órgão específico para legislar sobre políticas do livro didático: o Instituto Nacional do Livro $(\mathrm{INL})^{12}$. Tal constatação é relevante, pois coloca em evidência a preocupação do Estado com a educação e seu projeto de ampliação da demanda educacional pela adoção de manuais didáticos. Entre 1938 e 1985, período em que o atual Programa Nacional do Livro Didático (PNLD) foi colocado em prática ${ }^{13}$, vários decretos e acordos foram confeccionados a respeito

\footnotetext{
${ }^{10}$ A esse respeito é importante citar a contribuição de Rita de Cássia Cunha Ferreira por meio de sua dissertação de mestrado apresentada à Faculdade de Ciências e Letras da Universidade Estadual Paulista - UNESP. Intitulada: A Comissão Nacional do Livro Didático Durante o Estado Novo (1937-1945), defendida na cidade de Assis em 2008.

${ }^{11}$ A página do FNDE na internet esclarece que: "O Programa Nacional do Livro Didático (PNLD) é o mais antigo dos programas voltados à distribuição de obras didáticas aos estudantes da rede pública de ensino brasileira e iniciou-se, com outra denominação, em 1929. Ao longo desses 80 anos, o programa foi aperfeiçoado e teve diferentes nomes e formas de execução. Atualmente, o PNLD é voltado à educação básica brasileira, tendo como única exceção os alunos da educação infantil [...]”. Cf. Disponível em: <http://www.fnde.gov.br/index.php/pnldhistorico>

${ }^{12}$ Segundo informações do FNDE em "1929 - O Estado cria um órgão específico para legislar sobre políticas do livro didático, o Instituto Nacional do Livro (INL), contribuindo para dar maior legitimidade ao livro didático nacional e, consequentemente, auxiliando no aumento de sua produção". Cf. Disponível em: <http://www.fnde.gov.br/index.php/pnld-historico>

${ }^{13}$ Em 1985, com a edição do Decreto no 91.542, de 19/8/85, o PLIDEF (Programa do Livro Didático para o Ensino Fundamental) dá lugar ao Programa Nacional do Livro Didático (PNLD), que traz diversas mudanças,
} 
da produção e utilização do livro didático. Sobre isso, encontra-se no site oficial do FNDE a seguinte cronologia:

1945 - Pelo Decreto-Lei no 8.460, de 26/12/45, é consolidada a legislação sobre as condições de produção, importação e utilização do livro didático, restringindo ao professor a escolha do livro a ser utilizado pelos alunos, conforme definido no art. $5^{\mathrm{o}}$.

1966 - Um acordo entre o Ministério da Educação (MEC) e a Agência Norte Americana para o Desenvolvimento Internacional (Usaid) permite a criação da Comissão do Livro Técnico e Livro Didático (Colted), com o objetivo de coordenar as ações referentes à produção, edição e distribuição do livro didático. $\mathrm{O}$ acordo assegurou ao MEC recursos suficientes para a distribuição gratuita de 51 milhões de livros no período de três anos. Ao garantir o financiamento do governo a partir de verbas públicas, o programa adquiriu continuidade.

1970 - A Portaria n ${ }^{\circ}$ 35, de 11/3/1970, do Ministério da Educação, implementa o sistema de coedição de livros com as editoras nacionais, com recursos do Instituto Nacional do Livro (INL).

1971 - O Instituto Nacional do Livro (INL) passa a desenvolver o Programa do Livro Didático para o Ensino Fundamental (Plidef), assumindo as atribuições administrativas e de gerenciamento dos recursos financeiros até então a cargo da Colted. A contrapartida das Unidades da Federação torna-se necessária com o término do convênio MEC/Usaid, efetivando-se com a implantação do sistema de contribuição financeira das unidades federadas para o Fundo Nacional do Livro didático.

1976 - Pelo Decreto $n^{\circ} 77.107$, de 4/2/76, o governo assume a compra de boa parcela dos livros para distribuir a parte das escolas e das unidades federadas. Com a extinção do INL, a Fundação Nacional do Material Escolar (Fename) torna-se responsável pela execução do programa do livro didático. Os recursos provêm do Fundo Nacional de Desenvolvimento da Educação (FNDE) e das contrapartidas mínimas estabelecidas para participação das Unidades da Federação. Devido à insuficiência de recursos para atender todos os alunos do ensino fundamental da rede pública, a grande maioria das escolas municipais é excluída do programa.

1983 - Em substituição à Fename, é criada a Fundação de Assistência ao Estudante (FAE), que incorpora o Plidef. Na ocasião, o grupo de trabalho encarregado do exame dos problemas relativos aos livros didáticos propõe a participação dos professores na escolha dos livros e a ampliação do programa, com a inclusão das demais séries do ensino fundamental ${ }^{14}$.

Ainda de acordo com o portal do FNDE outras medidas foram tomadas pelo Estado após 1985; dentre elas é importante salientar a volta da universalização da distribuição do

como: Indicação do livro didático pelos professores, reutilização do livro, implicando a abolição do livro descartável e o aperfeiçoamento das especificações técnicas para sua produção, visando maior durabilidade e possibilitando a implantação de bancos de livros didáticos, extensão da oferta aos alunos de $1^{\mathrm{a}}$ e $2^{\mathrm{a}}$ séries das escolas públicas e comunitárias, fim da participação financeira dos Estados, passando o controle do processo decisório para a FAE e garantindo o critério de escolha do livro pelos professores. Informações disponíveis no site: Disponível em: 〈http://www.fnde.gov.br/index.php/pnld-historico〉.

${ }^{14}$ Cf. PNDE. Disponível em: http://www.fnde.gov.br/index.php/pnld-historico. 
livro didático em 1995. Na sequência, o ano de 1996 se destaca, pois foi quando começou a avaliação pedagógica pelo MEC dos livros inscritos para o PNLD, com a respectiva divulgação dos resultados nos Guias de Livros Didáticos, distribuídos nacionalmente para as escolas, com o objetivo de orientar os professores na escolha. Segundo o site do PNDE: "Esse procedimento foi aperfeiçoado, sendo aplicado até hoje. Os livros que apresentam erros conceituais, indução a erros, desatualização, preconceito ou discriminação de qualquer tipo são excluídos do Guia do Livro Didático”. (FNDE, 2012).

Diante dos pontos apresentados, observamos que, na atualidade, somos apontados como "o país que tem o maior programa de fornecimento de livro do mundo" (CASSIANO, 2004, p. 35). Sem dúvidas nossos números são gigantescos. Corroboram essa constatação os dados do orçamento previsto pelo FNDE para o ano de 2012, estimado em torno de 1,48 bilhões de reais ${ }^{15}$. A partir de 2012 o programa de distribuição não sofreu mudanças drásticas, todavia, cabe apontar a adoção de medidas com vistas à “estruturação e a operação de serviço virtual para disponibilização de obras digitais ${ }^{16}$ e outros conteúdos educacionais digitais para professores, estudantes e outros usuários da rede pública de ensino brasileira” (FNDE, 2016), as medidas deram ênfase ao Programa Nacional do Livro Didático (PNLD) e ao Programa Nacional Biblioteca da Escola (PNBE).

Diante disso, lembramos que nos últimos anos nossos gastos com a compra de livros escolares nunca estiveram abaixo de um bilhão de reais ${ }^{17}$. Acerca dos dispêndios em 2016, em resumo, o portal do FNDE dispõe que o total de gastos com a compra e distribuição dos livros escolares foi de $1.070 .864 .859,82 \mathrm{R}$ \$. As informações sobre o número de escolas e alunos

\footnotetext{
${ }^{15}$ De acordo com o site do FNDE: "Em 2011, o governo federal investiu R $\$ 1,3$ bilhão na compra, avaliação e distribuição dos livros didáticos do PNLD 2012, direcionado ao atendimento integral do ensino médio (inclusive EJA) e à complementação e reposição, no âmbito do ensino fundamental, dos livros anteriormente distribuídos (PNLD 2010 e PNLD 2011). No ensino médio, o investimento foi de R\$883,4 milhões. Já o ensino fundamental contou com o investimento de $\mathrm{R} \$ 443$ milhões. Ao todo, foram adquiridos 163 milhões de livros para atender a 37.422.460 alunos, inclusive na modalidade Educação de Jovens e Adultos (EJA)". Disponível em: http://www.fnde.gov.br/index.php/pnld-apresentacao

${ }^{16}$ Segundo o portal do FNDE, as propostas para o ano letivo de 2015, que foram lançadas em 2012, previam em edital "que as editoras podem apresentar obras multimídia, reunindo livro impresso e livro digital. A versão digital deve trazer o mesmo conteúdo do material impresso mais os objetos educacionais digitais, como vídeos, animações, simuladores, imagens, jogos, textos, entre outros itens para auxiliar na aprendizagem. $\mathrm{O}$ edital também permite a apresentação de obras somente na versão impressa, para viabilizar a participação das editoras que ainda não dominam as novas tecnologias. Esse material será destinado aos alunos e professores do ensino médio da rede pública". (FNDE, 2016).

${ }^{17}$ Os dados estatísticos sobre os gastos públicos com a compra e distribuição de livros escolares podem ser acessados por meio do seguinte endereço eletrônico: http://www.fnde.gov.br/programas/livro-didatico/livrodidatico-dados-estatisticos.
} 
beneficiados, assim como, os custos com aquisição e distribuição podem ser observados na tabela número 1:

Tabela 1: PNLD ano 2016

\begin{tabular}{|l|l|l|l|l|l|}
\hline $\mathrm{P}$ & Escolas & Alunos & Exemplares & Aquisição & Distribuição \\
$\mathrm{N}$ & Beneficiadas & Beneficiados & & & \\
$\mathrm{L}$ & & & & & \\
\hline $\begin{array}{l}\text { Ano } \\
2016\end{array}$ & 121.574 & 34.513 .075 & 128.588 .730 & $1.070 .680 .044,28 \mathrm{R} \$$ & $184.815,54 \mathrm{R} \$$ \\
\hline
\end{tabular}

Fonte: http://www.fnde.gov.br/programas/livro-didatico/livro-didatico-dados-estatisticos

Na imagem número 1, podemos observar um mapa que demonstra como foi realizada a distribuição dos livros didáticos em todo o país no ano de 2016:

\section{Imagem 1: Mapa PNLD 2016 - distribuição dos livros}

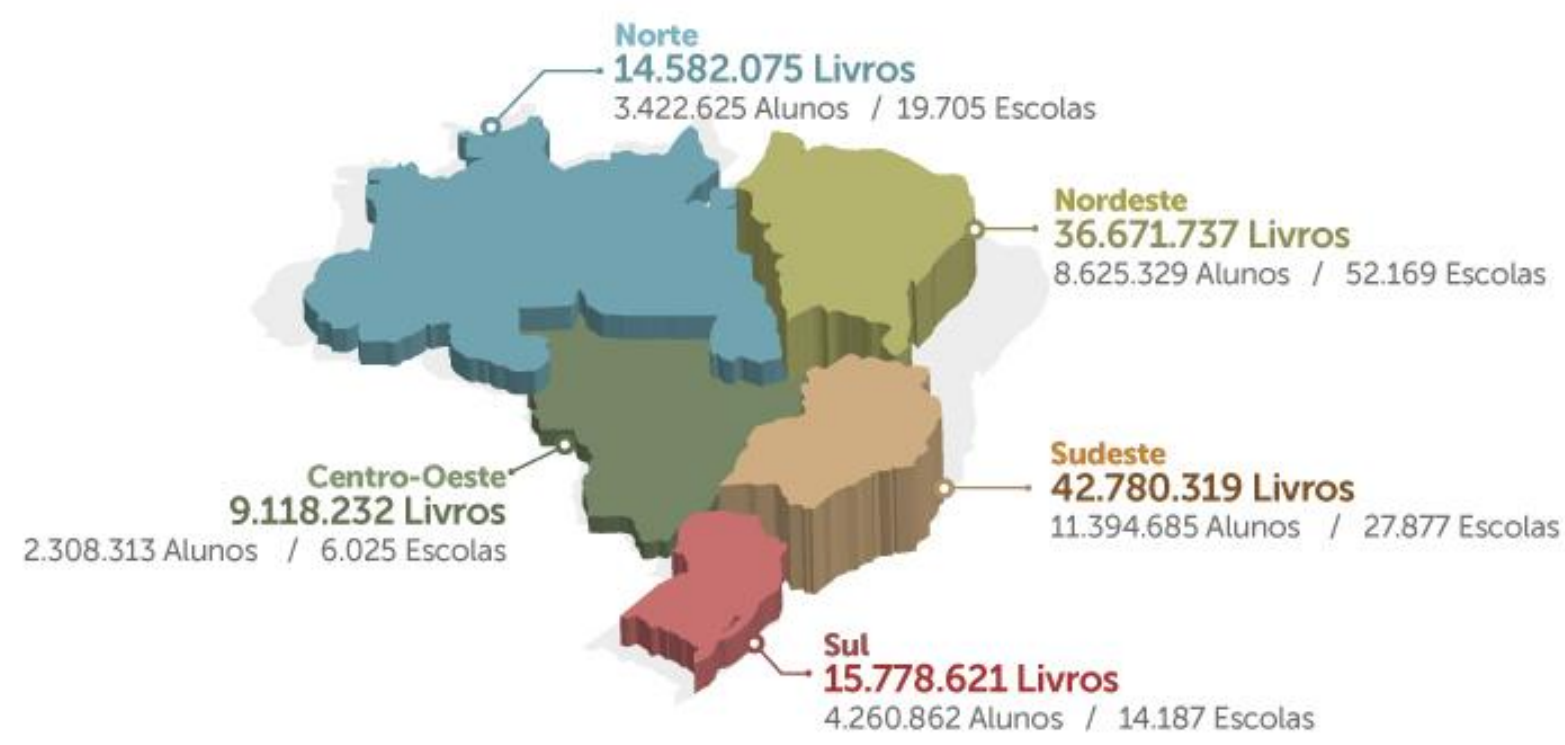

Fonte: http://www.fnde.gov.br/programas/livro-didatico.

Os dados apresentados nos oportuna perceber o grande empreendimento que é o programa de livros didáticos na educação brasileira. O maior volume de livros foi disponibilizado para a região sudeste. O que parece coerente, pois foram dispostos de forma 
proporcional ao grande número de alunos desta região. Em média são quase quatro livros didáticos por aluno nas diferentes regiões do país.

De qualquer maneira, antes de nos posicionarmos frente aos livros escolares, devemos compreender que estes materiais perpassam a esfera estritamente pedagógica, respondendo também a interesses de diversas empresas e partidos políticos. São estes alguns dos pontos que nos desafiam ao realizarmos pesquisas em História da Educação, mais especificamente quando nos debruçamos em investigar os instrumentos do trabalho didático.

\section{CONSIDERAÇÕES FINAIS}

No presente artigo abordamos algumas questões ligadas aos livros escolares e seu papel na organização do trabalho didático na escola contemporânea. Nossa revisão bibliográfica demonstrou a influência da proposta comeniana, expressa principalmente pelo emprego dos livros didáticos, na educação básica. Contudo, percebe-se que o livro didático, nos últimos anos, vem sofrendo diversas críticas. Mesmo assim, estes instrumentos ainda permanecem como os principais elementos do trabalho didático. O que evidencia, além da perspectiva didático-pedagógica, que tal instrumento responde também a interesses políticos e econômicos. Tendo em vista representarem a maior parte da receita das grandes editoras do setor.

Todavia, diante o que foi apresentado, percebemos que é possível o emprego de novas tecnologias que proporcionem a superação do livro impresso. Entretanto, frisamos que não basta somente erradicar o livro didático impresso das escolas, o que está em jogo é a superação da atual organização do trabalho didático, fundamentada no anacrônico modelo comeniano. Com base nisso, carecemos construir uma nova organização do trabalho didático, não excludente, mas acima de tudo que vise resgatar e dispor democraticamente o conhecimento sólido culturalmente significativo. É este, pois, o grande desafio que se coloca aos intelectuais da educação.

\section{REFERÊNCIAS BIBLIOGRÁFICAS}

APPLE, M. W. Trabalho docente e textos. Porto Alegre: Artes Médicas, 1995. 
ARAÚJO, Marta Maria de. Plasticidade do plano de reconstrução educacional de Anísio Teixeira 1952-1964. Educativa, Goiânia, v. 10, n. 1, p. 9-27, jan./jun. 2007.

ALVES, G. L. O trabalho didático na escola moderna: formas históricas. Campinas, SP: Autores Associados, 2005.

ALVES, G. L. ALVES, G. L. A produção da escola pública contemporânea. 2. ed. Campinas: Autores Associados, 2004. O pensamento burguês no Seminário de Olinda: 1800-1836. Campo Grande, MS: Editora UFMS; Campinas, SP: Autores Associados, 2001. Textos escolares e manuais didáticos comenianos. Texto apresentado na I Jornada de Estudos Sobre a Organização do Trabalho Didático. Campo Grande, 2011. . Textos escolares no Brasil, 2012.

As funções da escola pública de educação geral sob o imperialismo. Novos Rumos, São Paulo, n. 16, p. 89-112, 1990.

ALVES, Gilberto Luiz; CENTENO, Carla Villamaina. A produção de manuais didáticos de história do Brasil: remontando ao século XIX e início do século XX. Revista Brasileira de Educação, v. 14, n. 42, p. 469-487, set./dez. 2009.

BITTENCOURT, Circe Maria Fernandes. "Livros didáticos entre textos e imagens". In: . (Org.). O saber histórico na sala de aula. 2. ed. São Paulo: Contexto, 1998.

BRITO, Silvia Helena Andrade de [et al.] (Org.). A organização do trabalho didático na história da educação. Campinas, SP: Autores Associados, 2010.

BRITO, Silvia Helena Andrade de. O ensino de sociologia e a organização do trabalho didático no Colégio Pedro II (1925-1945). Revista Brasileira de História da Educação, v. 12, p. $95-124,2012$.

CASSIANO, Célia Cristina de Figueiredo. O mercado do livro didático no Brasil: da criação do Programa Nacional do Livro Didático (PNLD) à entrada do capital internacional espanhol (1985- 2007). 2007. 252f. Tese (Doutorado) - Pós-graduação Educação: História, Política e Sociedade da PUC - SP, São Paulo, 2007.

Aspectos políticos e econômicos da circulação do livro didático de história e suas implicações curriculares. História, São Paulo, V. 23, n. 1-2, 2004. Disponível em: <http://www.scielo.br/pdf/his/v23n1-2/a03v2312.pdf >. Acesso em 15 abr. 2011.

CENTENO, Carla Villamaina. O conhecimento histórico vulgarizado: a "ditadura" do manual didático. Revista HISTEDBR On-line, Campinas, n.33, p.169-178, mar.2009, 169-178. 
CENTENO, Carla Villamaina. O compêndio História do Brasil - Curso Superior de João Ribeiro: análise sob a perspectiva da organização do trabalho didático. Texto apresentado na I Jornada de Estudos Sobre a Organização do Trabalho Didático. Campo Grande, 2011.

Projeto ARARIBÁ. Revista HISTEDBR On-line, número especial, p. 20-35, mai. 2010- ISSN: 1676-2584.

Educação e Fronteira com o Paraguai na historiografia matogrossense (1870-1950). 2007. 257f. Doutorado) - Universidade Estadual de Campinas, Faculdade de Educação, Campinas, 2007.

COMENIUS, Iohannis Amos. Didáctica Magna. Trad. Joaquim Ferreira Gomes. Lisboa: Fundação Calouste Gulbenkian, 2001.

FERNANDES, José Ricardo Oriá. O livro didático e a pedagogia do cidadão: o papel do Instituto Histórico e Geográfico Brasileiro no ensino de História. Revista de História, v. 13, João Pessoa, jul./ dez. 2005.

FONSECA, T. de L. e. "O livro didático de História: Lugar de memória e formador de identidades”. In: SIMPÓSIO NACIONAL DA ASSOCIAÇÃO NACIONAL DE HISTÓRIA, 20, Florianópolis, 1999. História: fronteiras / Associação nacional de História. São Paulo: Humanitas, FFLCH, ANPUH, 1999.

GATTI JÚNIOR, Décio. A escrita escolar da história: o livro didático e ensino no Brasil (1970-1990). Bauru, SP: Edusc, Uberlancia, MG: Edufu, 2004.

MARX, Karl. O capital: crítica da economia política. Trad. Régis Barbosa e Flávio R. Kothe. São Paulo: Abril Cultural, 1983. V. I, T I. (Coleção os economistas).

MUNAKATA, Kasumi. O livro Didático como mercadoria. Pro-Posições, v. 23, n. 3 (69), p. 51-66 | set./dez. 2012. Disponível em: <http://www.scielo.br/pdf/pp/v23n3/04.pdf> acesso em $12 / \mathrm{jan} / 2015$.

LAJOLO, M.; ZILBERMAN, R. A formação da leitura no Brasil. São Paulo: Ática, 1999.

LANCILLOTTI, Samira Saad Pulchério. Manuais de psicologia como instrumentos de trabalho utilizados na formação dos professores paulistas (1920-1940). Cadernos de História da Educação (UFU. Impresso), v. 12, p. 29-44, 2013.

SAVIANI, Dermeval. História das idéias pedagógicas no Brasil. Campinas: Autores Associados, 2007.

SOUZA, Ana A. Arguelho de. "Manuais didáticos: formas históricas e alternativas de superação". In: BRITO, Silvia Helena Andrade de et al. A organização do trabalho didático na história da educação. (Org.). Campinas, SP: Autores Associados: HISTEDBR, 2010. 